\title{
Lauro-Aimé Colliard, Un jeune ami de Montaigne: Charles d'Estissac
}

\section{Filippo Fonio}

\section{Q OpenEdition}

1 Journals

\section{Edizione digitale}

URL: https://journals.openedition.org/studifrancesi/37482

DOI: 10.4000/studifrancesi.37482

ISSN: 2421-5856

\section{Editore}

Rosenberg \& Sellier

\section{Edizione cartacea}

Data di pubblicazione: 15 décembre 2004

Paginazione: 598

ISSN: 0039-2944

\section{Notizia bibliografica digitale}

Filippo Fonio, «Lauro-Aimé Colliard, Un jeune ami de Montaigne: Charles d'Estissac», Studi Francesi [Online], 144 (XLVIII | III) | 2004, online dal 30 novembre 2015, consultato il 08 mai 2021. URL: http:// journals.openedition.org/studifrancesi/37482 ; DOI: https://doi.org/10.4000/studifrancesi.37482

Questo documento è stato generato automaticamente il 8 mai 2021.

\section{(c) $(1) \&$}

Studi Francesi è distribuita con Licenza Creative Commons Attribuzione - Non commerciale - Non opere derivate 4.0 Internazionale. 
Lauro-Aimé Colliard, Un jeune ami de Montaigne: Charles d'Estissac

Filippo Fonio 


\section{NOTIZIA}

LAURO-AIMÉ COLLIARD, Un jeune ami de Montaigne: Charles d'Estissac, in Lingua, cultura e testo. Miscellanea di studi francesi in onore di Sergio Cigada, a cura di Enrica GALAZZI e Giuseppe BERNARDELLI, vol. II, t. 1, Milano, V \& P Università, 2003, pp. 273-284.

Oggetto del presente studio è la figura di Charles d'Estissac, un giovane annoverato fra i compagni di Montaigne nel viaggio in Italia che costui intraprese nel 1580, attraversando Francia, Svizzera, Germania, e del quale troviamo un resoconto nel Journal. Si tratta di un gentiluomo figlio di Louise de la Béraudière, amica di Montaigne, del quale sembra che questi si prendesse particolarmente cura. A Venezia, Firenze, Roma, d'Estissac è l'unico fra gli accompagnatori di Montaigne ad accompagnarlo nelle visite a personaggi altolocati e ad assistere alle cerimonie del gran mondo. Fra gli obiettivi di Montaigne nel suo viaggio in Italia vi era quello di crearsi una rete di contatti per poter aspirare a un'ambasciata, cosa che lo porta fra l'altro a intense frequentazioni nel periodo del suo soggiorno italiano, che si concluderà nell'ottobre 1581, in seguito alla sua nomina a Maire et Gouverneur di Bordeaux. D’Estissac lo accompagna per un tratto sulla via del ritorno, quindi fa ritorno a Roma per completare la propria educazione di gentiluomo e cortigiano à la Castiglione, in particolare frequentando le scuole d'armi italiane, allora molto in voga. Proprio in un duello al quale aveva preso parte in qualità di secondo, d'Estissac trova la morte, nel 1586, sulla strada tra Montrouge e Vaugirard. Quella dei duelli è una vera a propria piaga del tempo, contro la quale lo stesso Montaigne prende posizione, in particolare denunciando l'assurdità della difesa a oltranza dell'onore. Si tratta spesso di scontri nati per futili ragioni, proprio come quello in cui Charles d'Estissac trova la morte. 